\title{
Uniting Church And Family In The Great Commission
}

\author{
Hengky So, ${ }^{1 *}$ Benteng Martua Mahuraja Purba ${ }^{2}$ \\ Prodi PAK, STT Real Batam ${ }^{2}$ \\ hengkyss@yahoo.com
}

\begin{abstract}
The family and the Church are two institutions founded by God himself. As an institution consisting of family and church believers complement each other in carrying out the Great Commission. But in its journey the burden of carrying out the mission is often left to the church, many families do not carry out the Great Commission. This article discusses problems between the church and the family in carrying out the Great Commission mission, with the aim of the family being able to understand and embarrass the mission of the Great Commission in the family and outside the family.
\end{abstract}

Keywords: Family, Church, Institution, Great Commission.

\begin{abstract}
Abstrak
Keluarga dan Gereja merupakan dua lembaga yang didirikan oleh Allah itu sendiri. Sebagai lembaga yang terdiri dari orang-orang percaya kelaurga dan gereja saling melengkapi dalam melaksanakan Amanat Agung. Namun dalam perjalanannya sering sekali beban menjalankan misi diserahkan kepada gereja, banyak keluarga yang tidak melaksanakan Amanat Agung. Artikel ini membahas permasalahan antar gereja dengan keluarga dalam menjalankan misi Amanat Agung, dengan tujuan keluarga dapat memahami dan Malukan tugas misi Amanat Agung dalam keluarga maupun diluar keluarga.

Kata kunci: Keluarga, Gereja, Lembaga, Amanat Agung.
\end{abstract}

\section{PENDAHULUAN}

Ada dua lembaga yang dibentuk Tuhan yaitu keluarga dan gereja. Keluarga pertama dibentuk Tuhan di Taman Eden yaitu keluarga Adam dan Hawa (Kej 2:18) Sedangkan Gereja dibentuk Tuhan pada saat peristiwa Pentakosta di Yerusalem (Kis 2:1-13). Sebagai dua lembaga yang dibentuk Tuhan maka seyogianya keluarga dan gereja saling mendukung dan bersatu dalam menyelesaikan Amanat Agung. Tetapi faktanya tidak demikian. Pada masa ini pada umumnya hanya gereja yang melaksanakan Amanat Agung sedang masih banyak keluarga yang tidak melaksanakannya. Kalaupun ada keluarga yang melaksanakan 
Amanat Agung maka jumlahnya sangat sedikit dan sering hanya oknum keluarga yang melaksanakan dan bukan lembaga keluarganya. Beberapa alasan mengapa keluarga belum melaksanakan Amana Agung adalah:

- Keluarga tidak memahami bahwa Amanat Agung adalah panggilan dan tugas keluarga.

- Keluarga tidak peduli dengan Amanat Agung atau tidak peduli dengan jiwa jiwa yang terhilang.

- Keluarga memiliki pergumulan sendiri misalnya pergumulan ekonomi, karier dan lain sebagainya.

- Keegoisan keluarga yang hanya memperhatikan diri sendiri dan tidak memiliki perhatian kepada orang lain.

- Keluarga belum dewasa rohani dan masih hidup secara duniawi.

Selanjutnya hubungan menjadi dasar penting baik dalam keluarga maupun Gereja seperti yang dijelaskan oleh Fredy Simanjuntak, pola hubungan merupakan inti dari seluruh pelayanan dan kehadiran Yesus selama melakukan seluruh pekerjaanNya di Bumi. Yesus dalam kesehariannya menempatkan diri-Nya di tengah-tengah orang banyak, mulai dari keluarga sampai kepada anak-anak. ${ }^{1}$

\section{HASIL DAN PEMBAHASAN}

\section{Amanat Agung}

Amanat Agung atau Great Commission adalah bagian penting dalam kehidupan kekristenan. Martin dalam Hartono mengatakan bahwa pertumbuhan gereja terjadi karena melaksanakan Amanat Agung secara khusus pertumbuhan secara kuantitaif. ${ }^{2}$ Amanat Agung berisikan perintah supaya setiap orang pecaya melakukan pemberitaan Injil. Amanat agung itu merupakan tugas yang diberikan kepada Yesus kepada setiap orang percaya, dalam Matius 28:19-20 mandat itu tidak hanya ditujukan kepada setiap orang yang mengikuti-Nya. Namun Munthe berpendapat tidak sedikit orang Kristen justru menganggap melaksanakan amanat agung adalah tugas hamba Tuhan. ${ }^{3}$

\section{Keluarga}

Seperti yang suda dijabarkan diatas bahwa keluarga merupakan lembaga yang dibentuk oleh Tuhan. Selain itu keluarga merupakan lingkungan pertama yang

\footnotetext{
1 Fredy Simanjuntak, "Problematika Disorganisasi Dan Disharmonisasi Keluarga," in Keluarga Yang Misioner, 2018, 81-

2 Handreas Hartono, "Mengaktualisasikan Amanat Agung Matius 28 : $19-20$ Dalam Konteks Era Digital," KURIOS (Jurnal Teologi dan Pendidikan Agama Kristen) 4, no. 2 (2018): 157-166, www.sttpb.ac.id/ejournal/index.php/kurios. 158

3 Eben Munthe, "Mengoptimalkan Karunia Dalam Jemaat Untuk Melakukan Misi Amanat Agung Di Era 4.0," EPIGRAPHE: Jurnal Teologi dan Pelayanan Kristiani 3, no. 2 (2019): 133-141.134
} 
penting bagi setiap orang bila ditinjau dari sudut pandang agama maupun sosial kemasyarakatan. Terlebih lagi dalam Ulangan 6:7 diajarkan agar keluarga itu sejak dini menanamkan pengetahuan atau pengenalan akan Tuhan yang baik, dalam lingkungan sosial kemasyarakatan maka termasuk juga kepribadain, dan moral anak dipengaruhi oleh keluarga. Maka dengan demikian Amanat Agung itu juga merupakan bagian dari panggilan tanggung jawab keluarga Kristen agar setiap bagian keluarga mendengar Injil, dimuridkan, dan melakukan misi Amanat Agung tersebut.

\section{Keluarga Melaksanakan Amanat Agung}

Ketika keluarga melaksanakan Amanat Agung maka harus diperhatikan dua hal yaitu:

\section{Keluarga Melaksanakan Amanat Agung Melalui Keluarga.}

Yang dimaksud dengan keluarga melaksanakan Amanat Agung melalui keluarga adalah keluarga menjangkau jiwa-jiwa atau keluarga-keluarga yang belum percaya dan menjadikannya murid Kristus. Sebenarnya panggilan melaksanakan Amanat Agung adalah panggilan dari Tuhan untuk keluarga. Dalam Kejadian 1:28 Tuhan memberikan mandate misi kepada keluarga Adam dan Hawa yang saya yakini bahwa mandate misi ini bukan hanya untuk keluarga Adam dan Hawa saja tetapi juga untuk semua keluarga orang percaya. Alkitab memberikan contoh keluarga Priskila dan Akwila yang melaksanakan Amanat Agung setelah mereka menjadi orang percaya. Tadinya mereka bukan orang percaya. Mereka adalah pengusaha kemah dan merupakan teman bisnis Paulus. Paulus menginjili dan memuridkan mereka sehingga akhirnya mereka menjadi teman sekerja Paulus dalam memberitakan Injil. (Roma 16,3). Mereka bukan saja memenangkan jiwa tetapi mereka juga memuridkan jiwa-jiwa tersebut di rumah mereka (Roma 16:5). Setiap keluarga harus menyadari bahwa Tuhan memanggil keluarga untuk melaksanakan Amanat Agung dan memuridkan orang orang yang dimenangkannya untuk Tuhan.

\section{Keluarga Melaksanakan Amanat Agung Di Dalam Keluarga}

Hal kedua yang perlu diperhatikan oleh keluarga yang melaksanakan Amanat Agung adalah Amanat agung harus dilaksanakan di dalam keluarga sendiri. Banyak orang yang sangat sibuk melaksanakan Amanat Agung kepada orang lain tetapi sayangnya orang tersebut tidak melaksanakannya di dalam keluarganya sendiri sehingga orang lain diselamatkan oleh Injil tetapi keluarganya sendiri mengalami kebinasaan. Amanat Agung bukan hanya berisi perintah bersaksi dan memenangkan jiwa tetapi juga mengandung perintah untuk 
memuridkan orang percaya. Jadi keluarga juga harus dimuridkan. Alkitab mencatat tentang keberhasilan imam Eli memuridkan Samuel sehingga di bawah bimbingannya Samuel menjadi nabi yang dipakai Tuhan. Sayangnya Imam Eli tidak berhasil memuridkan kedua anaknya karena kedua anaknya Hofni dan Pinehas menjadi imam yang cabul dan korup (1 Sam 2:22-25). Kisah kegagalan imam Eli harusnya menjadi pelajaran untuk kita orang percaya masa kini supaya kita jangan hanya giat memuridkan orang lain tetapi lupa memuridkan keluarga kita. Alkitab memberikan banyak contoh bahwa Tuhan ingin supaya Amanat agung dilaksanakan di dalam keluarga. Kornelius adalah perwira Romawi yang diselamatkan oleh Injil. Ternyata Kornelius mengajak keluarganya saat dia tahu bahwa Petrus akan datang ke rumahnya mengabarkan Injil. Hal itu menyebabkan keluarganya juga memberi diri dibaptis (Kis 10:24,48). Demikian juga Lidia, dia dan seisi rumahnya menjadi orang percaya setelah mendengar injil yang disampaikan Paulus (Kis 16:15). Juga demikian halnya dengan kepala penjara di kota Filipi. Dia membawa Paulus dan Silas ke rumahnya sehingga seisi rumahnya menjadi orang percaya (Kis 16:34). Contoh lain adalah Filipus, salah seorang dari tujuh orang yang terpilih untuk pelayanan diakonia pada gereja mula mula. Filipus adalah seorang yang giat melaksanakan Amanat Agung di luar dan di dalam rumahnya. Dia memiliki empat anak perempuan yang juga melayani Tuhan dengan karunia bernubuat (Kis 21:8-9). Jadi sangat jelas bahwa Amanat Agung harus dilaksanakan di dalam keluarga. Bagaimana keluarga dimuridkan?

1. Dengan mengajarkan Firman Tuhan (Ul 6:6-7).

Jika diperhatikan maka sebenarnya Ulangan 6:6-7 adalah perintah Tuhan kepada setiap orang tua supaya mereka mengajarkan Firman Tuhan kepada anak anak mereka. Sayangnya ada banyak orang tua yang tidak melaksanakan Ulangan 6. Banyak orang tua yang menyerahkan tanggung jawab ini kepada guru guru Sekolah Minggu di gereja. Itulah sebabnya banyak orang tua yang menuntut gereja supaya menyediakan program Sekolah Minggu yang bagus dengan harapan anak anak mereka bisa bertumbuh rohaninya. Dan tidak sedikit orang tua yang akhirnya pindah beribadah ke gereja lain karena program Sekolah Minggu gereja itu lebih baik. Kalau kita mau kembali kepada Ulangan 6:6-7 maka seharusnya orangtualah yang paling bertanggung jawab mengajarkan Firman kepada anak anaknya. Guru Sekolah Minggu hanya sebagai penolong yang melengkapi saja. Jadi orangtua harus memuridkan anak anaknya dengan mengajarkan Firman supaya anak anaknya mengenal kebenaran Firman. Karena itu orang tua harus mengerti Firman dan kaya dengan Firman supaya bisa mengajarkannya kepada anak anaknya. 


\section{Menjadi Role Model}

Orang tua harus menjadi contoh dan teladan untuk anak anaknya. Untuk menjadi contoh dan teladan orang tua harus menunjukan perbuatan yang sesuai dengan ajarannya. Orang tua bukan hanya mengajar anak-anaknya dengan katakata tetapi juga dengan perbuatan dan tindakan. Bukankah khotbah melalui perbuatan lebih nyaring bunyinya dari pada seribu khotbah yang terbaik? Dengan menjadi role model maka orang tua bisa memuridkan anak-anaknya dengan efektif.

\section{Uniting Church And Family In The Great Commission}

Sering kali tanpa disadari telah terjadi kompetisi antara Gereja dan keluarga. Ada anak-anak yang menganggap Gereja adalah kompetitornya dalam hal merebut perhatian orang tua karena orang tuanya menghabiskan waktu lebih banyak untuk melayani di Gereja dari pada menemani dirinya di rumah. Demikian juga ada suami yang menganggap istrinya lebih tunduk kepada Gereja dari pada kepada dirinya. Atau ada isteri yang menganggap suaminya lebih cinta Gereja dari pada dirinya karena suaminya selalu murah hati menyumbang Gereja sementara sangat pelit kepada dirinya. Tentunya kompetisi kedua lembaga ini harus diakhiri. Gereja dan keluarga harus bersatu dalam melaksanakan Amanat Agung. Wujud persatuan itu bisa dilakukan dengan cara :

1. Gereja memperlengkapi keluarga dengan:

- Pengajaran Firman Tuhan sehingga keluarga menjadi kuat dan bertumbuh rohaninya dan mengerti panggilannya untuk melaksanakan Amanat Agung.

- Pementoran kepada keluarga sehingga keluarga mendapat pendampingan dan bimbingan dari Gereja dalam melaksanakan Amanat Agung.

- Pelatihan-pelatihan misalnya pelatihan penginjilan pribadi, pelatihan parenting kepada orang tua dan lain-lain sehingga keluarga memiliki keterampilan dalam melaksanakan amanat Agung baik di dalam maupun di luar keluarga.

2. Keluarga mendukung Gereja dengan:

- SDM yang dimiliki keluarga seperti suami atau isteri dan anak anak yang bisa melayani di Gereja. Tentunya SDM dari keluarga ini adalah SDM yang berkualitas, bertalenta dan berkarakter sehingga bisa mendukung Gereja.

- Dana yang bisa disumbangkan untuk pelayanan Gereja. Pelayanan misi membutuhkan dana. Dengan menyumbangkan dana maka keluarga dapat mendukung menyelesaikan Amanat Agung. 


\section{KESIMPULAN}

Gereja dan keluarga adalah dua lembaga yang dibentuk oleh Tuhan. Pengkhotbah 4:9 berkata bahwa berdua lebih baik dari pada seorang diri. Demikian juga Gereja dan keluarga harusnya melayani bersama sama dalam melaksanakan Amanat Agung. Ketika Gereja dan keluarga bersatu dan saling mendukung dalam melaksanakan Amanat Agung maka penyelesaian Amanat Agung bisa lebih cepat dituntaskan.

\section{KEPUSTAKAAN}

Hartono, Handreas. "Mengaktualisasikan Amanat Agung Matius 28 : 19-20 Dalam Konteks Era Digital." KURIOS (Jurnal Teologi dan Pendidikan Agama Kristen) 4, no. 2 (2018): 157-166. www.sttpb.ac.id/ejournal/index.php/kurios.

Munthe, Eben. "Mengoptimalkan Karunia Dalam Jemaat Untuk Melakukan Misi Amanat Agung Di Era 4.0." EPIGRAPHE: Jurnal Teologi dan Pelayanan Kristiani 3, no. 2 (2019): 133-141.

Donald Guthrie, Teologi Perjanjian Baru 1, Allah, Manusia, Kristus, Bpk Gunung Mulia (Jakarta, 19920

Ensiklopedia Alkitab Masa Kini, jilid I A-L, Yayasan Komunikasi Bina Kasih/OMF (Jakarta,1992)

Peter Scazzero, Gereja Yang Sehat Secara Emosional, Gospel Press (Batam, 2005) Ben Freudenburg, Family Friendly Church ( Yayasan Patmos,1995)

Simanjuntak, Fredy. "Problematika Disorganisasi Dan Disharmonisasi Keluarga." In Keluarga Yang Misioner, 81-91, 2018. 